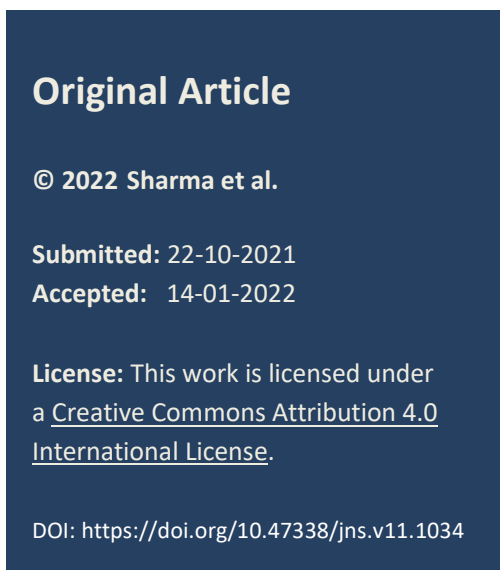

\title{
Congenital intrinsic duodenal obstruction: Clinical study and predictors of neonatal surgical mortality
}

Pramila Sharma, Naresh Pawar, ${ }^{*}$ Arun Kumar Gupta

Department of Pediatric Surgery, SMS Medical College, Jaipur, Rajasthan, India

Correspondence*: Dr. Naresh Pawar, Plot no 3, second block, Om Nagar, Kalaburagi, Karnataka, India. E-mail: nareshp221@gmail.com

\author{
KEYWORDS \\ Congenital duodenal \\ obstruction, \\ Duodenal atresia, \\ Duodenal web, \\ Duodenoduodenostomy, \\ Neonatal surgical mortality
}

\section{ABSTRACT}

Background: This study was aimed to analyze the clinical profile and the predictors of neonatal surgical mortality of congenital intrinsic duodenal obstruction (CIDO).

Methods: This is a case series of 67 patients with CIDO (duodenal atresia and stenosis) admitted at our teaching institute, from October 2018 to June 2020. The demographic data, clinical presentation, diagnostic methods, location \& type of duodenal atresia, the operative procedure performed, and neonatal surgical mortality (NSM) predictors such as birth weight, age on presentation, associated anomalies, duration of surgery, extubation after surgery, sepsis, and vasopressors support were analyzed.

Results: Of 67 patients, $40(60 \%)$ were premature; mean weight and age at presentation were $2.06 \pm 0.6(1-8 \mathrm{~kg})$ and 6.7 (1-240days), respectively. The majority of patients $(59,88 \%)$ presented with vomiting, and the most common finding on the $\mathrm{x}$-ray abdomen was a double bubble sign $(54,81 \%)$. Twenty-four $(36 \%)$ were associated with congenital heart disease and $19(28 \%)$ had Down's syndrome. Type 3 duodenal atresia was the commonest finding in $43(64 \%)$ followed by type 1 in $22(33 \%)$, and type 2 in $2(3 \%)$. In 49 (73\%) Kimura's duodenoduodenostomy, excision of web \& duodenoplasty in $13(19 \%)$, and side to side duodenoduodenostomy in $4(6 \%)$, were performed. The mean hospital stay of survivors was 9 days. Overall survival was $63 \%$.

Conclusion: Type 3 duodenal atresia is the commonest variety observed. The prematurity, low birth weight, associated major congenital anomalies, surgery $>90$ minutes, delayed extubation after surgery, sepsis, and need for vasopressors support are significant predictors of NSM.

\section{INTRODUCTION}

Congenital intrinsic duodenal obstruction (CIDO - Duodenal atresia $\&$ stenosis) is one of the common surgical congenital anomalies in newborns and infants as characterized by repeated bilious emesis. [1,2] Over half of the patients have associated major congenital anomalies and syndromes such as Down syndrome, congenital cardiac anomalies, and gastrointestinal anomalies. [3-6] It is often associated with maternal polyhydramnios, prematurity, and low birth weight. [7]

Over the years, the prognosis of neonates and infants with CIDO has improved markedly, which is attributed to several factors such as early diagnosis, improved surgical techniques, and improved perioperative management by neonatologists, including the availability of neonatal intensive care unit (NICU), total parenteral nutrition (TPN) and neonatal anesthesia in developed countries. [3] Several factors, however, still affect the overall outcome including prematurity, low birth weight, a high incidence of associated anomalies, and reoperations. $[8,9]$ The aims of the study were to analyze the clinical profile including demography, clinical presentation, operative findings, postoperative complications, and the predictors of outcome of congenital intrinsic duodenal obstruction.

\section{METHODS}

This is a clinical observational study comprising 67 consecutive cases of intrinsic duodenal obstruction. After IRB approval, the patients for the study were selected from the pediatric surgical unit of a tertiary care center from October 2018 to June 2020.

All patients (institutional \& referred) with neonatal intestinal obstruction (NIO) were admitted to NICU. Pa- 
tients were optimized and evaluated as per institutional protocol viz plain X-ray abdomen (typical double bubble appearance) (Fig. 1A), ultrasonography (USG) abdomen (to rule out associated malrotation, urogenital anomalies, and annular pancreas), routine blood investigations.

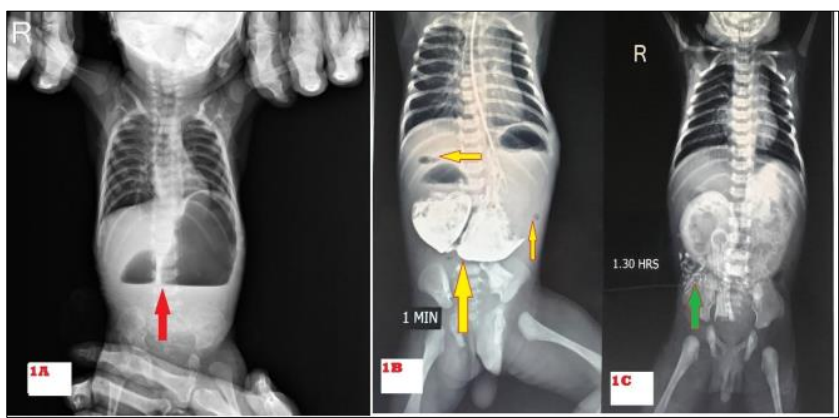

Figure 1: A) Double bubble sign (Red arrow). B \& C) Gastrografin upper GI contrast study- hugely dilated stomach and duodenum with intrinsic obstruction as a smooth and rounded end at D2 with distal air (yellow arrow)/ contrast (green arrow) without distal beaking effect into D3.

Once the diagnosis of duodenal obstruction was made, demographic data was recorded as age at presentation, weight at presentation, birth weight, antenatal history, clinical presentation, x-ray abdomen, and baby gram findings. Bedside 2D Echo was done in all patients who had murmur on auscultation and who were hemodynamically unstable. In rest of the patients, it was done post-discharge on OPD basis. Water-soluble contrast (Gastrografin) upper gastrointestinal (UGI) study was done to confirm partial duodenal obstruction due to perforated duodenal web when in doubt. UGI endoscopy was done in one patient (presented with a history of ingestion of foreign body, the perforated duodenal web was incidental finding). Down's syndrome was suspected based on clinical features and karyotyping was done for affordable patients. Exploratory laparotomy was performed in all patients, intraoperative type of duodenal atresia and associated anomaly if the present were noted. Either kimura's duodenoduodenostomy (KDD) or side to side duodenoduodenostomy was performed for duodenal atresia. Excision of web and Heineke-Mikulicz duodenoplasty (EW\&HMD) was performed for the duodenal web. Other procedures were performed for associated congenital anomalies like isolated esophageal atresia (IEA), tracheo-esophageal fistula (TEF), anorectal malformation (ARM), malrotation, and other bowel atresia. Postoperatively, the clinical course, complications, and outcome as discharged alive or expired were noted. We analyzed the predictors of outcome variables as gestational age (term $\geq 37$ or preterm $<37$ weeks) [10], prenatal or postnatal diagnosis of duodenal obstruction, birth weight (normal weight $\geq 2500$ or LBW $1500-2499$ or VLBW $<1500$ grams) [11], age on presentation, associated anomalies, duration of surgery (<90 minutes or $>90$ minutes), extubation after surgery (on table or $<24$ hours or $>24$ hours), post-operative sepsis and vasopressors support.

Inclusion criteria: All patients with an intraoperative finding of intrinsic duodenal obstruction were included in the study.

The statistical analysis was done using Microsoft Excel (XLSTAT). The mean, range, percentage, standard deviation, and chi-square tests were analyzed. The $\mathrm{P}$ value $<0.05$ was considered statistically significant.

\section{RESULTS}

Of 67 patients, 39 were male and 28 were female with a male to female ratio of $1.4: 1$. The demographic characteristics of the patients are shown in Table 1. The common presenting features on presentation were vomiting in 59 (88\%) of which 44 had bilious and 15 had non-bilious vomiting, and epigastric bulge in 52 (77\%) (Fig. 2). Double bubble appearance on X-ray abdomen was seen in 54 (81\%) (Fig. 1A). Seven infants had distended stomach and duodenum with gas in the small bowel on abdominal x-ray. Abdominal USG color Doppler was done to rule out malrotation. Six underwent a gastrografin upper GI contrast study which gave suspicion of the perforated duodenal web (Fig. 1B, 1C). One patient underwent Upper GI endoscopy which showed windsock deformity with a small hole on the web along with a foreign body. The inability to insert stiff red rubber catheter beyond $10 \mathrm{~cm}$ per orally with double bubble appearance on of babygram was observed in 7 patients. A single bubble was found in 5 cases. In the patient with IEA, the diagnosis of CIDO was made during feeding gastrostomy, in which the infant feeding tube was not negotiable beyond the second part of the duodenum; moreover, the stomach and duodenum were dilated and filled with bile mixed mucus.

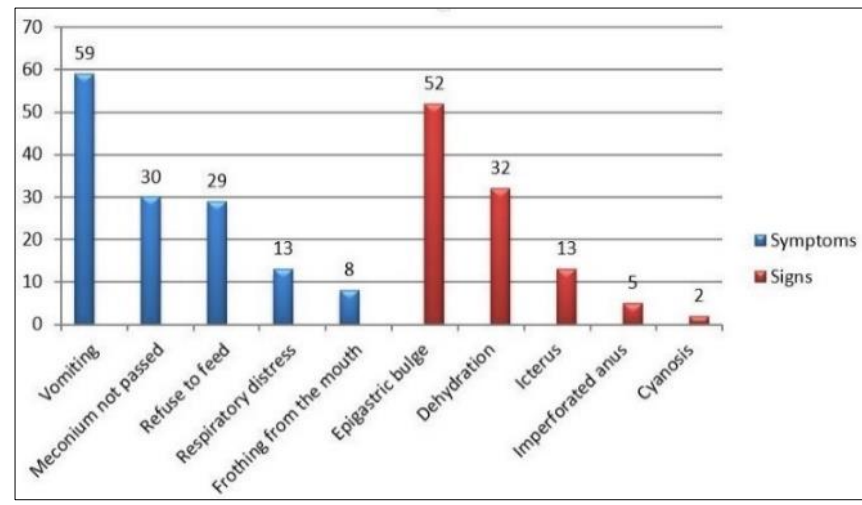

Figure 2. The spectrum of presentations of duodenal atresia.

On exploratory laparotomy, type 3 duodenal atresia was found in $43(64 \%)$ followed by type 1 in $22(33 \%)$, of which 15 had web and 7 had stenosis, and type 2 which was seen in 2 (3\%) patients (Fig. 3A, 3B, 3C). The location of duodenal atresia was pre-ampullary in $16(24 \%)$ and post-ampullary in 51 (76\%). The most common associated anomalies were CHD in 24 (36\%) 
and Down's syndrome in 19 (28\%), followed by gastrointestinal in 17 (25\%), urogenital anomalies in 7 (10\%), and limb defects in 7 (10\%), as shown in Table 2 . Three patients had triple atresia and 4 patients had VACTERL association. [12]

Table 1: Showing the Demography

\begin{tabular}{|l|l|}
\hline \multicolumn{2}{|c|}{ Demography overview } \\
\hline Total no of patients, (n) & $\begin{array}{l}67 \mathrm{Male}-39, \mathrm{Fe}- \\
\text { male }-28\end{array}$ \\
\hline Male:Female & $1.4: 1$ \\
\hline Gestational age at birth, weeks (range) & $35(28-40) \mathrm{SD} \pm 2.7$ \\
\hline History of polyhydramnios $\mathrm{n},(\%)$ & $25(37)$ \\
\hline $\begin{array}{l}\text { Weight at presentation in neonates / ne- } \\
\text { onates \& infants, } \mathrm{kg}(\mathrm{range})\end{array}$ & $\begin{array}{l}1.80 \pm 0.6(1-3 \mathrm{~kg}) / \\
2.06 \pm 0.6(1-8 \mathrm{~kg})\end{array}$ \\
\hline Normal weight, $\mathrm{n},(\%)$ & $11(16)$ \\
\hline Low birth weight $\mathrm{n},(\%)$ & $49(73)$ \\
\hline Very low birth weight $\mathrm{n},(\%)$ & $07(11)$ \\
\hline Premature $\mathrm{n},(\%)$ & $40(60)$ \\
\hline Prenatal suspicious of CDO $\mathrm{n},(\%)$ & $23(34)$ \\
\hline $\begin{array}{l}\text { Mean age at presentation in neonates, } \\
\text { days (range for infants) }\end{array}$ & $6.7(1-240)$ \\
\hline $\begin{array}{l}\text { Mean age at surgery in neonates, days } \\
\text { (range for infants) }\end{array}$ & $7.6(1-240)$ \\
\hline $\begin{array}{l}\text { Average length of hospital stay, days } \\
\text { (range) }\end{array}$ & $10.2(2-37)$ \\
\hline
\end{tabular}

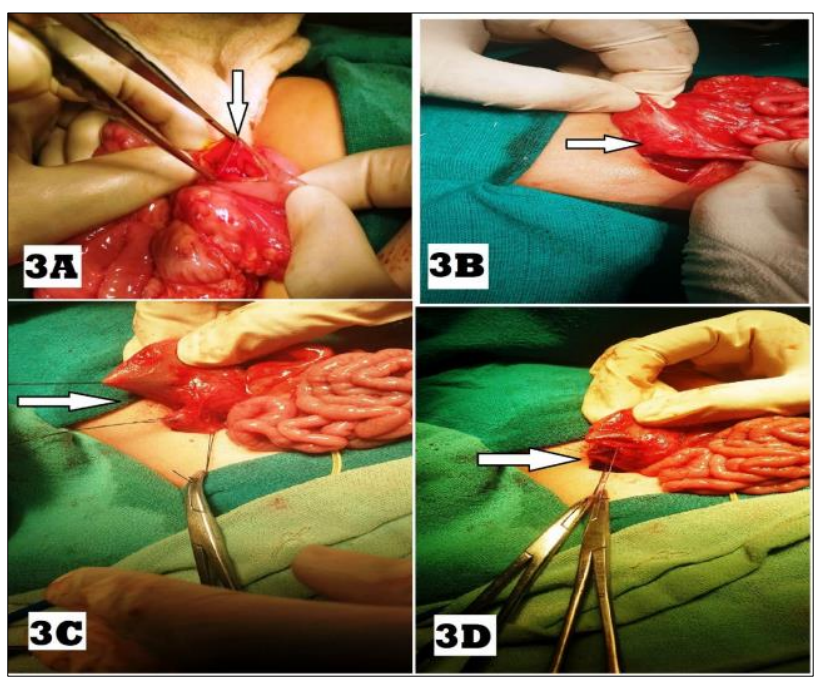

Figure 3. Different types of duodenal atresia. A) Duodenal web/ Type 1atresia with intact bowel wall and mesentery. B) Type 2 atresia- two ends connected by fibrous tissue in between without breach in the mesentery. C) Type 3 atresia - V-shaped mesenteric defect between blind ends. D) Kimura's technique.

The operative procedures performed for duodenal atresia and associated anomalies are shown in Table 3 . The procedure performed for duodenal atresia included Kimura's duodenoduodenostomy in 49 (73\%) (Fig. 3D) followed by EW \& HMD in 13 (19\%) and side to side duodenoduodenostomy in $4(6 \%)$. Duodenojejunos- tomy was performed in a cases as reoperation after Ladd's procedure (1st diagnosis malrotation) on a postoperative day 8 for the missed diagnosis of the perforated duodenal web, which was suggested by upper GI study done on postoperative day 6 .

Table 2: Showing associated anomalies

\begin{tabular}{|c|c|}
\hline ANOMALIES & No. of patients $\mathrm{n}(\%)$ \\
\hline Congenital heart disease & $24(36 \%)$ \\
\hline Down's syndrome & $19(28 \%)$ \\
\hline Gastrointestinal anomalies & $17(25 \%)$ \\
\hline $\begin{array}{l}\text { Tracheo-esophageal fistula + Isolated } \\
\text { esophageal atresia }\end{array}$ & $7+1=8$ \\
\hline Anorectal malformations & 5 \\
\hline Annular pancreas & 4 \\
\hline Malrotation & 2 \\
\hline Small bowel atresia & 2 \\
\hline Pyloric web & 1 \\
\hline Meckel's diverticulum & 1 \\
\hline Choledochal cyst & 1 \\
\hline Urogenital anomalies, Total & $7(10 \%)$ \\
\hline Hydronephrosis & 3 \\
\hline Single kidney & 2 \\
\hline Hypospadias with Undescended testis & 2 \\
\hline Limb anomalies, Total & $7(10 \%)$ \\
\hline Club foot & 4 \\
\hline Radial club hand & 1 \\
\hline Absent right hand & 1 \\
\hline Syndactyly & 1 \\
\hline $\begin{array}{l}\text { Triple atresia (esophageal, duodenal } \\
\text { and anal atresia in single patient) }\end{array}$ & 3 \\
\hline VACTERL association & 4 \\
\hline
\end{tabular}

Forty-two (63\%) patients were discharged alive and 25 $(37 \%)$ expired. Common events in the postoperative course of survivors were the start of TPN on Day 2 (Day1-Day5), NS enema on Day 3 (Day2-Day4), the passage of meconium Day 4 (Day3-Day11), NG removal on Day 6 (Day5-Day14), the start of feed on Day 7 (Day5-Day 14) and discharge on Day 9 (Day7-Day16). The most common postoperative complication was sepsis in 19 (28\%), followed by pneumonia in 17 (25\%), functional obstruction, and wound infection in $8(12 \%)$. None of the patients showed evidence of an anastomotic leak. The analysis of predictors of mortality is shown in Table 4. In neonates with triple atresia and VACTERL association, the mortality was $100 \%$. 
Table 3. Showing operative procedures performed for duodenal atresia as well as associated anomalies and outcome

\begin{tabular}{|l|c|c|}
\hline Surgery & No. cases & Survival (\%) \\
\hline KDD & 42 & $33(78 \%)$ \\
\hline KDD with Left transverse colostomy & 1 & 0 \\
\hline KDD with TEF surgery & 3 & 0 \\
\hline KDD with TEF surgery \& Left transverse colostomy & 2 & 0 \\
\hline KDD with TEF surgery with end to back jejunoileal anastomosis & 1 & 0 \\
\hline Side to side duodenoduodenostomy & 4 & $2(50 \%)$ \\
\hline Excision of web and HMD & 10 & $5(50 \%)$ \\
\hline Excision of web and HMD with Ladd's procedure & 1 & $1(100 \%)$ \\
\hline Excision of web and HMD with cervical esophagostomy and tube gastrostomy & 1 & 0 \\
\hline $\begin{array}{l}\text { Multiple Heineke Mikulicz procedures for pyloric web, duodenal web \& multiple small } \\
\text { and large bowel atresia with Choledochal tube cystostomy }\end{array}$ & 1 & 0 \\
\hline Duodenojejunostomy with Ladd's procedure & 67 & $1(100 \%)$ \\
\hline Total & $\mathbf{4 2}(\mathbf{6 3} \%)$ \\
\hline
\end{tabular}

Note: TEF surgery was done simultaneously with KDD and/or with Left transverse colostomy for anorectal malformations (avoided in two cases of anovestibular fistula), End to back Jejunoileal anastomosis for type 1 jejunoileal atresia and Ladd's procedure for malrotation. KDD-Kimura's duodenoduodenostomy; TEF-Tracheo-esophageal fistula; HMD-Heineke Mikulicz duodenoplasty.

Table 4. Analytical data of predictor of mortality of patients with congenital intrinsic duodenal obstruction.

\begin{tabular}{|c|c|c|c|c|}
\hline Predictors of outcome & Total no. of patients & $\begin{array}{l}\text { No. of survivors } \\
\mathrm{n}(\%)\end{array}$ & $\begin{array}{l}\text { No. of Mortality } \\
n(\%)\end{array}$ & $\begin{array}{l}\text { Chi-square test } \\
P \text { value }(<0.05)\end{array}$ \\
\hline $\begin{array}{l}\text { Diagnosis of CDO } \\
\text { Antenatal } \\
\text { Post natal }\end{array}$ & $\begin{array}{l}23 \\
44\end{array}$ & $\begin{array}{l}14 \\
28\end{array}$ & $\begin{array}{l}09(39 \%) \\
16(36 \%)\end{array}$ & 0.82 \\
\hline $\begin{array}{l}\text { Age on presentation (days) } \\
\text { Less than } 3 \text { days } \\
3-7 \text { days } \\
8-28 \text { days } \\
\text { More than } 28 \text { days }\end{array}$ & $\begin{array}{l}27 \\
18 \\
16 \\
06\end{array}$ & $\begin{array}{l}15 \\
13 \\
13 \\
05\end{array}$ & $\begin{array}{l}12(44 \%) \\
05(28 \%) \\
03(18 \%) \\
01(17 \%)\end{array}$ & 0.19 \\
\hline $\begin{array}{l}\text { Gestational age (weeks) } \\
\text { Term }(\geq 37) \\
\text { Preterm }(<37)\end{array}$ & $\begin{array}{l}27 \\
40 \\
\end{array}$ & $\begin{array}{l}23 \\
19 \\
\end{array}$ & $\begin{array}{l}04(15 \%) \\
21(52 \%)\end{array}$ & 0.007 \\
\hline $\begin{array}{l}\text { Birth weight (grams) } \\
\text { Normal birth weight }(\geq 2500) \\
\text { Low birth weight }(1500-2499) \\
\text { Very low birth weight }(1000-1499)\end{array}$ & $\begin{array}{l}11 \\
49 \\
07\end{array}$ & $\begin{array}{l}10 \\
32 \\
00\end{array}$ & $\begin{array}{l}01(9 \%) \\
17(35 \%) \\
07(100 \%)\end{array}$ & 0.0004 \\
\hline $\begin{array}{l}\text { Associated anomalies } \\
\text { Down's syndrome } \\
\text { CHD } \\
\text { TEF/IEA } \\
\text { Others }\end{array}$ & $\begin{array}{l}19 \\
24 \\
08 \\
17\end{array}$ & $\begin{array}{l}09 \\
07 \\
00 \\
04\end{array}$ & $\begin{array}{l}10(53 \%) \\
17(70 \%) \\
08(100 \%) \\
13(76 \%)\end{array}$ & $\begin{array}{l}0.122 \\
0.031 \\
0.02 \\
0.0142\end{array}$ \\
\hline $\begin{array}{l}\text { Duration of surgery (minutes) } \\
\text { Less than } 90 \\
\text { More than } 90\end{array}$ & $\begin{array}{l}49 \\
18 \\
\end{array}$ & $\begin{array}{l}37 \\
5\end{array}$ & $\begin{array}{l}12(24 \%) \\
13(72 \%)\end{array}$ & 0.0003 \\
\hline $\begin{array}{l}\text { Extubation after surgery } \\
\text { On OT table } \\
\text { Less than } 24 \text { hours } \\
\text { More than } 24 \text { hours /not extubated }\end{array}$ & $\begin{array}{l}41 \\
09 \\
17 \\
\end{array}$ & $\begin{array}{l}33 \\
06 \\
04 \\
\end{array}$ & $\begin{array}{l}08(19 \%) \\
03(33 \%) \\
13(76 \%) \\
\end{array}$ & 0.0002 \\
\hline $\begin{array}{l}\text { Post op Infection } \\
\text { No sepsis } \\
\text { sepsis }\end{array}$ & $\begin{array}{l}48 \\
19 \\
\end{array}$ & $\begin{array}{l}39 \\
3\end{array}$ & $\begin{array}{l}09(18 \%) \\
16(84 \%) \\
\end{array}$ & $<0.0001$ \\
\hline $\begin{array}{l}\text { Vasopressor support required } \\
\text { No } \\
\text { Yes }\end{array}$ & $\begin{array}{l}40 \\
27 \\
\end{array}$ & $\begin{array}{l}39 \\
03\end{array}$ & $\begin{array}{l}01(2.5 \%) \\
24(88 \%) \\
\end{array}$ & $<0.0001$ \\
\hline Total no. of patients & 67 & $42(63 \%)$ & $25(37 \%)$ & \\
\hline
\end{tabular}

CDO- congenital duodenal obstruction; CHD- congenital heart disease; TEF/IEA- tracheo-esophageal atresia/isolated esophageal atresia; OT-operating table. 
Prenatal diagnosis: Twenty-three (34\%) neonates had a suspicion of duodenal obstruction on prenatal USG, while $44(66 \%)$ were diagnosed postnatally. The prenatal diagnosis of CIDO was not a significant predictor of mortality with a p-value $>0.05$.

Age at presentation: Twenty-seven (40\%) presented within 24-72 hrs, 18 (27\%) between 3-7days, 16 (24\%) between 8 - 28days and 6 (9\%) presented after 28days of life. Age at presentation was not a significant predictor of mortality with a p-value $>0.05$.

Gestational age: Most babies were preterm 40 (60\%) $<37$ weeks while 27 (40\%) were born at term. The mortality was $5(15 \%)$ in term neonates while 21 (52\%) in preterm babies. The mortality was significantly high amongst preterm neonates with a $\mathrm{p}$-value of $<0.05$.

Birth weight: Eleven (16\%) neonates had normal weight ( >2500gm), 49(73\%) had LBW (1500-2499gm), and 7 (11\%) had VLBW (<1500gm). The mortality was only $1(9 \%)$ for normal weight, 17 (35\%) in LBW, and 7(100\%) in VLBW babies. In VLBW and LBW babies mortality was high compared to normal weight with a p-value $<0.05$.

Associated anomalies: Amongst major associated anomalies, the mortality was $17(70 \%)$ for $\mathrm{CHD}$, and $8(100 \%)$ for TEF/IEA, independently and/ or in combination with Down's syndrome (p-value $<0.05)$.

Duration of surgery: The patients who required a longer duration of surgery (>90 minutes) had more mortality compared to patients requiring less duration (p-value <0.05).

Extubation after surgery: Forty-one (61\%) patients were extubated after completion of the procedure, 9 (14\%) within 24 hours, and $17(25 \%)$ after 24 hours or could not be extubated at all with respective mortality as $8(19 \%), 3(33 \%)$, and $13(76 \%)$. Mortality was found to be high in patients who were extubated 24 hours after surgery (or could not be extubated at all) ( $\mathrm{p}$-value $<0.05)$.

Sepsis: The mortality was $16(84 \%)$ in patients who developed sepsis compared to $9(18 \%)$ who did not have sepsis. The patients with sepsis were associated with significantly higher mortality (p-value $<0.0001)$. Infection with Gram-negative, Gram-positive, and fungal organisms was seen in $16(84.2 \%), 2(12.5 \%)$, and 1 patient, respectively.

Vasopressors support: Twenty-seven (40\%) patients required higher doses of dopamine and dobutamine with/without adrenaline for hemodynamic instability, and $40(60 \%)$ did not. The mortality was $24(88 \%)$ and $1(2.5 \%)$ in those who required vasopressors and those who did not. The patients requiring vasopressors were associated with significantly higher mortality ( $\mathrm{p}$-value $<0.0001)$.

\section{DISCUSSION}

The incidence of CIDO is 1 in 5000 to 10,000 live births with a male preponderance. [6, 13, 14] Error in the recanalization of obliterated duodenal lumen due to rapid proliferation of epithelium during the sixth week of development thought to be the primary cause. [2] Usually, the atresia, as well as the stenosis, is limited to the first and second part of the duodenum. They are relatively uncommon proximal to the ampulla of Vater, the most common site being just at the ampulla. Multiple atresias are less frequent. [6]

In our study, The CIDO was found more in males, the same trend was reported by other series. [1, 4, 5, 7] Twenty-five (37\%) patients in our study, had a history of maternal polyhydramnios, the same was observed by other authors. [3, 7] The age of presentation varies depending upon whether the obstruction is partial or complete. Duodenal atresia presents earlier as compared to duodenal stenosis or perforated duodenal web/diaphragm [15], the same was observed in this series. Girvan and Stephens documented LBW in more than fifty percent of neonates with duodenal obstruction [16], the same was found in our study. Our series had prematurity in $40(60 \%)$ babies in accordance with study by Al-Salem et al. [17]

Preoperative X-ray abdomen showing a double bubble sign is diagnostic of duodenal obstruction. It was sufficient to diagnose $54(81 \%)$ patients in this study. Duodenal web with hole (centric or eccentric) was diagnosed by gastrografin meal follow-through in 6 patients and in one by UGI endoscopy.

In our study, type 3 duodenal atresia was the commonest type (64\%) followed by type 1 (33\%) and type $2(3 \%)$; similar was observed by Gupta et al. [19] and Garg et al. [20] But in other series, type 1 duodenal atresia was the frequent type of duodenal atresia. [1, 3-5, 7-9, $16,17]$

Although survival of duodenal atresia corrected surgically has been more than $95 \%$ according to western data published recently by Bethel et al. [20], in this study it was 63\%. Survival of patients in Gupta et al. was $61 \%$, which is comparable to our study. [18] In most of the developed countries, LBW, VLBW, preterm, gestational age in surgical newborns has become an obsolete parameter in the prognostic risk categorization. However, in developing countries LBW and prematurity still remain important determinants for neonatal surgical mortality (NSM).

Most of the studies failed to show a causal relationship between age at presentation, delay in seeking treatment, and NSM as was also the case in this study $(\mathrm{P}>$ 
0.05). [22-24] Puri et al observed that LBW and premature babies were associated with a higher probability of NSM. [21] The same was observed in this study.

The presence of associated life-threatening anomalies is a significant predictor as these anomalies (mainly cardiac anomalies) can cause death unrelated to the anomaly. Such decompensation is precipitated by anesthesia and surgical stress. In this study, babies who had major associated congenital anomalies had significantly higher NSM independently or in combination with Down's syndrome (p-value < 0.05). Similar was observed in other studies. [9, 21]

Neonatal stress response to surgery is the most important determinant of hormonal and metabolic changes following surgery which have a bearing on mortality and morbidity [25]. The longer duration of surgery (>90minutes) and multiple surgeries for associated surgical emergencies were significant predictors of NSM ( $\mathrm{p}$-value $<0.05$ ). Impaired neonatal respiratory physiology is an important risk factor for neonatal mortality. About $39 \%$ of neonates required postoperative mechanical ventilation and $25 \%$ required it for $>24 \mathrm{~h}$. Postoperative mechanical ventilation $>24$ hours had high NSM compared to infants who did not require or require $<24$ hours support. Similar observations were observed by other studies. [21, 26] In the present study, infants with sepsis and who require vasopressors support were $28 \%$ and $40 \%$, respectively. Of these infants, $84 \%$ and $88 \%$ respectively had NSM ( $p$-value

\section{REFERENCES}

1. Al-Salem AH. Congenital intrinsic duodenal obstruction: a review of 35 cases. Ann Saudi Med. 2007; 27:289-92.

2. Applebaum H, Sydorak R. Duodenal atresia and stenosisannular pancreas. In: Coron AG, editor. Pediatric surgery, 7th ed. Philadelphia: Elsevier; 2012. p. 1051-7.

3. Dalla Vecchia LK, Grosfeld JL, West KW, Rescorla FJ, Scherer LR, Engum SA. Intestinal atresia and stenosis: a 25year experience with 277 cases. Arch Surg. 1998; 133:4907 .

4. Mustafawi AR, Hassan ME. Congenital duodenal obstruction in children: a decade's experience. Eur J Pediatr Surg. 2008; 18:93-7.

5. Choudhry MS, Rahman N, Boyd P, Lakhoo K. Duodenal atresia: associated anomalies, prenatal diagnosis and outcome. Pediatr Surg Int. 2009; 25:727-30.

6. Ogle SB, Nichol PF, Ostlie DJ. Duodenal and intestinal atresia and stenosis. In: Holcomb III GW, editor. Holcomb and Ashcraft's Pediatric Surgery, 7th ed. China: Elsevier; 2020. P. 489-506.

7. Hancock BJ, Wiseman NE. Congenital duodenal obstruction: The impact of an antenatal diagnosis. J Pediatr Surg. 1989; 24:1027-31.

8. Bailey PV, Tracy TF, Connors TR, Monney DP, Lewis JE, Weber TR: Congenital duodenal obstruction: A 32-year review. J Pediatr Surg. 1993; 28:92-5.

9. Akhtar J, Guiney EJ. Congenital duodenal obstruction. Br J Surg. 1992; 79:133-5.

10. Moutquin JM. Classification and heterogeneity of preterm birth. BJOG. 2003; 110:30-3.
$<0.0001)$. The Same was documented by other studies. [21-22]

The limitation of this study was that karyotyping was not done in many patients due to affordability issues. Moreover, these neonates were cared by pediatric surgeons instead of neonatologists. The follow-up data collection after discharge from the hospital was not possible as most parents were of poor socioeconomic class and did not turn up for follow-up.

\section{CONCLUSION}

Congenital intrinsic duodenal obstruction commonly presents with bilious vomiting, epigastric fullness, and double bubble sign on plain $\mathrm{x}$-ray abdomen. Type $3 \mathrm{du}-$ odenal atresia is the most common variety encountered. Prematurity, LBW, associated major congenital anomalies, duration of surgery $>90$ minutes, delayed extubation after surgery, sepsis, and vasopressors support are significant predictors of NSM in our setting.

\section{Acknowledgements: Nil. \\ Conflict of Interest: None.}

Source of Support: Nil

Consent to Publication: Author(s) declared taking informed written consent for the publication of clinical photographs/material (if any used), from the legal guardian of the patient with an understanding that every effort will be made to conceal the identity of the patient, however it cannot be guaranteed.

Author Contributions: Author(s) declared to fulfil authorship criteria as devised by ICMJE and approved the final version.

11. Cutland CL, Lackritz EM, Mallett-Moore T, Bardaji A, Chandrasekaran R, Lahariya C, et al. Brighton Collaboration Low Birth Weight Working Group. Low birth weight: Case definition \& guidelines for data collection, analysis, and presentation of maternal immunization safety data. Vaccine. 2017; 35:6492-500.

12. Pawar N, Singh AP, Gupta AK, Tanger R. VACTERL association with left pulmonary agenesis in an infant. Formos J Surg. 2019; 52:232-4.

13. Partridge E, Hedrick HL. Duodenal atresia and stenosis. In: Losty PD, editor. Rickham's Neonatal Surgery, 1st ed. London: Springer; 2018. P. 675-81.

14. Al-Salem AH. Congenital duodenal obstruction. In: Al-Salem AH. editor. Atlas of Pediatric Surgery - Principles and treatment, 1st ed. Cham: Springer; 2020. P. 433-44.

15. Bales $\mathrm{C}$, Liacouras $\mathrm{CA}$. Intestinal atresia, stenosis, and malrotation. In Kliegman RM editor. Nelson's Textbook of Pediatrics, 20th ed. Philadelphia: WB Saunders, 2016. P. 1800-1.

16. Girvan DP, Stephens CA. Congenital intrinsic duodenal obstruction: a twenty-year review of its surgical management and consequences. J Pediatr Surg. 1974; 9:833-9.

17. Al-Salem AH, Khwaja S, Grant C, Dawodu A. Congenital intrinsic duodenal obstruction: problems in the diagnosis and management. J Pediatr Surg. 1989; 24:1247-9.

18. Gupta S, Gupta R, Ghosh S, Gupta AK, Shukla A, Chaturvedi V, et al. Intestinal atresia: Experience at a busy center of North-West India. J Neonatal Surg. 2016; 5:51. 
19. Garg D, Barolia DK, Singh AP, Mathur V. Neonatal intestinal obstruction - our institutional experience. Int J Med Sci Innov Res. 2019; 4:144-50.

20. Bethell GS, Long AM, Knight M, Hall NJ; BAPS-CASS. Congenital duodenal obstruction in the UK: a populationbased study. Arch Dis Child Fetal Neonatal Ed. 2020; 105:178-83.

21. Puri A, Lal B, Nangia S. A pilot study on neonatal surgical mortality: A multivariable analysis of predictors of mortality in a resource-limited setting. J Indian Assoc Pediatr Surg. 2019; 24:36-44.

22. Catre D, Lopes MF, Madrigal A, Oliveiros B, Viana JS, Cabrita AS, et al. Early mortality after neonatal surgery: Analysis of risk factors in an optimized health care system for the surgical newborn. Rev Bras Epidemiol. 2013; 16:94352 .

23. Ilori IU, Ituen AM, Eyo CS. Factors associated with mortality in neonatal surgical emergencies in a developing tertiary hospital in Nigeria. Open J Pediatr. 2013; 3:231-5.

24. Manchanda V, Sarin YK, Ramji S. Prognostic factors determining mortality in surgical neonates. J Neonatal Surg. 2012; 1:3.

25. Anand KJ, Aynsley-Green A. Measuring the severity of surgical stress in newborn infants. J Pediatr Surg. 1988; 23:297-305.

26. Snaidauf J, Kalousova J, Styblova J, Fryc R, Pycha K, Petru $\mathrm{O}$, et al. Results of treatment of esophageal atresia. Cas Lek Cesk. 2004; 143:614-7. 